Check for updates

Cite this: RSC Adv., 2017, 7, 32399

Received 27th March 2017

Accepted 16th June 2017

DOI: $10.1039 / \mathrm{c} 7 \mathrm{ra0} 3513 f$

rsc.li/rsc-advances

\section{In situ reactive interfacial compatibilization of polylactide/sisal fiber biocomposites via melt- blending with an epoxy-functionalized terpolymer elastomer}

\author{
Mingyang Hao, D ab Hongwu Wu*ab and Zhihua Zhu ${ }^{\text {ab }}$
}

The in situ reactive interfacial compatibilization and properties of polylactide/sisal fiber biocomposites made via melt blending with an epoxy-functionalized terpolymer elastomer, ethylene/methyl acrylate/ glycidyl methacrylate (EGMA), were investigated. Scanning electron microscopy results showed that the introduction of EGMA improved the interfacial adhesion between the sisal fibers (SF) and matrix, which was ascribed to the improved interfacial compatibilization between the polylactide and fibers via in situ reaction with EGMA during the melt-blending processing. It was also observed that the EGMA tends to weld on the surface of the fibers, which is called a self-weld fiber structure. The interfacial reaction and microstructure of the composites were further investigated by FTIR characterization, and thermal and rheological analyses. The results demonstrated that the mobility of the polylactide molecular chain was restricted due to the enhanced interfacial interaction of the composites. The addition of EGMA improved the toughness of the polylactide/sisal fiber composites without much decline in the tensile strength. Polylactide/sisal fiber composites with a good stiffness-toughness balance were obtained.

\section{Introduction}

Increasing awareness about environmental and sustainability issues throughout the world has a great impact on material engineering and design. Natural fibers have attracted extensive attention due to their ecological and renewable nature. The development of natural fiber-reinforced polymer composites is increasing worldwide, due to their low cost, light weight, nontoxicity, ability to be recycled, good structural properties and so on. ${ }^{1-4}$ They have great potential to replace synthetic fiber reinforced polymer composites.

The generally poor compatibility and interfacial adhesion between natural fibers and polymer matrix was one of the main drawbacks of natural fiber-reinforced polymer composites due to the hydrophilic nature of natural fibers. ${ }^{5,6}$ Numerous studies have proved that good interfacial adhesion is of great importance for obtaining good mechanical properties of composites materials. ${ }^{7}$ The interfacial adhesion greatly influences the stress transferability from polymer matrix to fibers in composites. Poor interfacial interactions between polymer matrix and the fiber surface are the most important mechanism of bond failure, because the interfacial defects can act as stress

${ }^{a}$ The Key Laboratory of Polymer Processing Engineering of Ministry of Education, South China University of Technology, Guangzhou, China. E-mail: mmhwwu@scut.edu.cn

${ }^{b}$ National Engineering Research Center of Novel Equipment for Polymer Processing, South China University of Technology, Guangzhou, China concentrators. ${ }^{8}$ Chemical treatment was considered as a effective way to improve the compatibility and interfacial adhesion of natural fiber-reinforced polymer composites. ${ }^{9}$ Many chemical treatment methods had been carried out on natural fibers, including silane treatment, ${ }^{10,11}$ acetylation treatment, ${ }^{12}$ benzoylation treatment, ${ }^{13}$ acrylation and acrylonitrile grafting, ${ }^{14,15}$ dopamine treatment, ${ }^{16} \mathrm{~N}$-methylol acrylamide grafting ${ }^{4}$ and so on. These chemical treatment methods could improve the interfacial adhesion of natural fibers and polymer matrix, while they sometimes weaken the fiber strength itself, and these methods were generally inefficiency and the solvents used in these methods are usually not friendly to environment. Reaction processing can improve the interfacial compatibility of composites via in situ reaction during melt-blending processing, thus it is a promising method to prepare natural fibrereinforced polymer composites without the disadvantages of chemical treatment methods.

Natural fiber-reinforced polylactide (PLA) composite is a kind of green and fully biodegradable material. But the low toughness of natural fiber-reinforced PLA is a disadvantage for application due to the inherent brittleness and low toughness of PLA. It has been demonstrated that reactive blending can be an efficient method to improve the toughness of PLA. ${ }^{17-20}$ In this study, biodegradable polylactide was used as polymer matrix and a functionalized reactive copolymer elastomer containing epoxy groups, ethylene/methyl acrylate/glycidyl methacrylate terpolymer (EGMA), was introduced into polylactide/sisal fiber 
(PLA/SF) composites. The presence of EGMA has potential to improve the interfacial compatibility of composites and the toughness of natural fiber-reinforced PLA via in situ reaction with natural fiber and PLA during melt-blending. The phase morphology, interfacial reaction, thermal and rheological behaviors, and mechanical properties of composites were investigated.

\section{Experimental section}

\subsection{Materials}

PLA (4032D, D-isomer content 1.2-1.6\%, $1.25 \mathrm{~g} \mathrm{~cm}^{-3}$ ) was supplied by NatureWorks (Minnesota, USA). It was vacuum dried at $80{ }^{\circ} \mathrm{C}$ for $8 \mathrm{~h}$ before use. The chopped sisal fibers (6 $\mathrm{mm}$ ) were obtained from Dongfang Sisal Co. (Guangdong, China) and Table 1 shows the properties of the fibers provided by supplier. Random terpolymer (LOTADER® AX 8900, Arkema lnc, France) of $68 \mathrm{wt} \%$ ethylene, $24 \mathrm{wt} \%$ methyl acrylate and 8 wt\% glycidyl methacrylate was used.

\subsection{Preparation of the composites}

Sisal fibers were soaked in sodium hydroxide solution (5 wt\%) for $1 \mathrm{~h}$ to remove lignin, pectin and waxy substances on sisal fibers surface, then vacuum dried at $80{ }^{\circ} \mathrm{C}$ for $8 \mathrm{~h}$ before use. Melt blending of PLA, EGMA and sisal fibers was carried out using an internal mixer (Poton 100, China) at $210{ }^{\circ} \mathrm{C}$ for $6 \mathrm{~min}$ with roller speed of $80 \mathrm{rpm}$. A series of PLA/SF/EGMA composites and PLA/EGMA binary blends with different EGMA content were prepared. After that, the obtained mixtures were compression molded at $200{ }^{\circ} \mathrm{C}$ for 3 min under $10 \mathrm{MPa}$ into standard specimens for rheological and mechanical tests.

\subsection{Measurements of mechanical properties}

Notched Izod impact tests were performed following the ISO 180 , using a $5.5 \mathrm{~J}$ pendulum at room temperature. The tensile tests were carried out on a universal tensile testing machine (Instron 5566, USA) according to ISO 527-2 with a crosshead speed of $2 \mathrm{~mm} \mathrm{~min}^{-1}$. At least five specimens for each composite were tested.

\subsection{Morphological characterization}

The fractured surfaces of specimens after the Izod impact tests and tensile tests were used for morphological characterization. Scanning electron microscope (SEM, FEI Quatan 250, USA) was employed to characterize the fracture surfaces morphology of PLA/SF/EGMA composites and PLA/EGMA blends. The impact

Table 1 Properties of sisal fibers

\begin{tabular}{lllll}
$\begin{array}{l}\text { Fiber } \\
\text { diameter } \\
(\mu \mathrm{m})\end{array}$ & $\begin{array}{l}\text { Fiber density } \\
\left(\mathrm{g} \mathrm{cm}^{-3}\right)\end{array}$ & $\begin{array}{l}\text { Cellulose } \\
\text { content }(\%)\end{array}$ & $\begin{array}{l}\text { Hemicellulose } \\
\text { content }(\%)\end{array}$ & $\begin{array}{l}\text { Lignin } \\
\text { content }(\%)\end{array}$ \\
\hline $25-200$ & 1.45 & $67-78$ & $10-14$ & $8-11$
\end{tabular}

and tensile fracture surfaces were sputter-coated with a gold layer before SEM observation to provide enhanced conductivity.

The phase morphologies of the dispersed EGMA and SF in PLA matrix were further examined by transmission electron microscope (TEM, JEOL 2100F, Japan). PLA/EGMA blends and PLA/SF/EGMA composites with 10 wt\% EGMA content were cryo-microtomed at $-60{ }^{\circ} \mathrm{C}$ to obtain ultrathin sections, and then subjected to TEM observation directly.

\subsection{The FT-IR measurement}

In order to prove the interfacial compatibilization between the PLA and fibers via reaction with EGMA during the meltblending processing, the sisal fibers were obtained from composites by Soxhlet extraction using dichloromethane as solvent and dried at $80{ }^{\circ} \mathrm{C}$ for $8 \mathrm{~h}$ in vacuum oven for the FT-IR analysis. The FT-IR (Nexus 670, Thermo Nicolet Co. Ltd, USA, $\mathrm{KBr}$ powder) was used to characterize the extracted fibers over a range of $4000-400 \mathrm{~cm}^{-1}$. For comparison, FTIR characterization of PLA and EGMA resin were also performed.

\subsection{Thermal analysis}

A differential scanning calorimeter (DSC 204C, NETZCH, Germany) was used to analyze the crystallization behavior of PLA/ SF/EGMA composites and PLA/EGMA blends under nitrogen flow. For nonisothermal crystallization, the samples were first heated from room temperature to $190{ }^{\circ} \mathrm{C}$ and held for $5 \mathrm{~min}$ at $190{ }^{\circ} \mathrm{C}$ to eliminate the thermal history, followed by cooling back to $40{ }^{\circ} \mathrm{C}$ at a rate of $10{ }^{\circ} \mathrm{C} \min ^{-1}$, after $2 \min$ in $40{ }^{\circ} \mathrm{C}$, the second heating scan from $40{ }^{\circ} \mathrm{C}$ to $190{ }^{\circ} \mathrm{C}$ at $10^{\circ} \mathrm{C} \min ^{-1}$ was performed. The cooling-crystallization of PLA/SF/EGMA composites at $5{ }^{\circ} \mathrm{C} \min ^{-1}$ was also carried out. For isothermal melt crystallization, the samples were heated from $30{ }^{\circ} \mathrm{C}$ to $190{ }^{\circ} \mathrm{C}$ and held for $5 \mathrm{~min}$ at $190{ }^{\circ} \mathrm{C}$ to eliminate the thermal history, and then cooled to $110{ }^{\circ} \mathrm{C}$ at a rate of $50{ }^{\circ} \mathrm{C} \mathrm{min}^{-1}$ and held for a period of time until the isothermal crystallization was complete. In the whole process, all samples were kept under

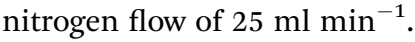

\subsection{Rheological characterization}

Linear rheological tests were performed by a dynamic oscillatory rheometer (Anton paar, MCR 302, Austria), equipped with a plate diameter of $25 \mathrm{~mm}$ and a gap of $1 \mathrm{~mm}$ parallel plate geometry. Small-amplitude oscillatory shear (SAOS) measurements were carried out from $0.0628 \mathrm{rad} \mathrm{s}^{-1}$ to $628 \mathrm{rad} \mathrm{s}^{-1}$ at $180{ }^{\circ} \mathrm{C}$ with strain amplitude of $1 \%$.

\section{Results and discussion}

\subsection{Morphology analysis}

The impact fracture surfaces of PLA/SF and PLA/SF/EGMA composites with different EGMA content were examined by SEM and shown in Fig. 1. For the PLA/SF composites without EGMA addition, many fibers were directly pulled out from PLA matrix when the composites were broken, and many holes were formed in the fracture surfaces, as can be seen from Fig. 1a. These phenomena indicating the poor interfacial adhesion 

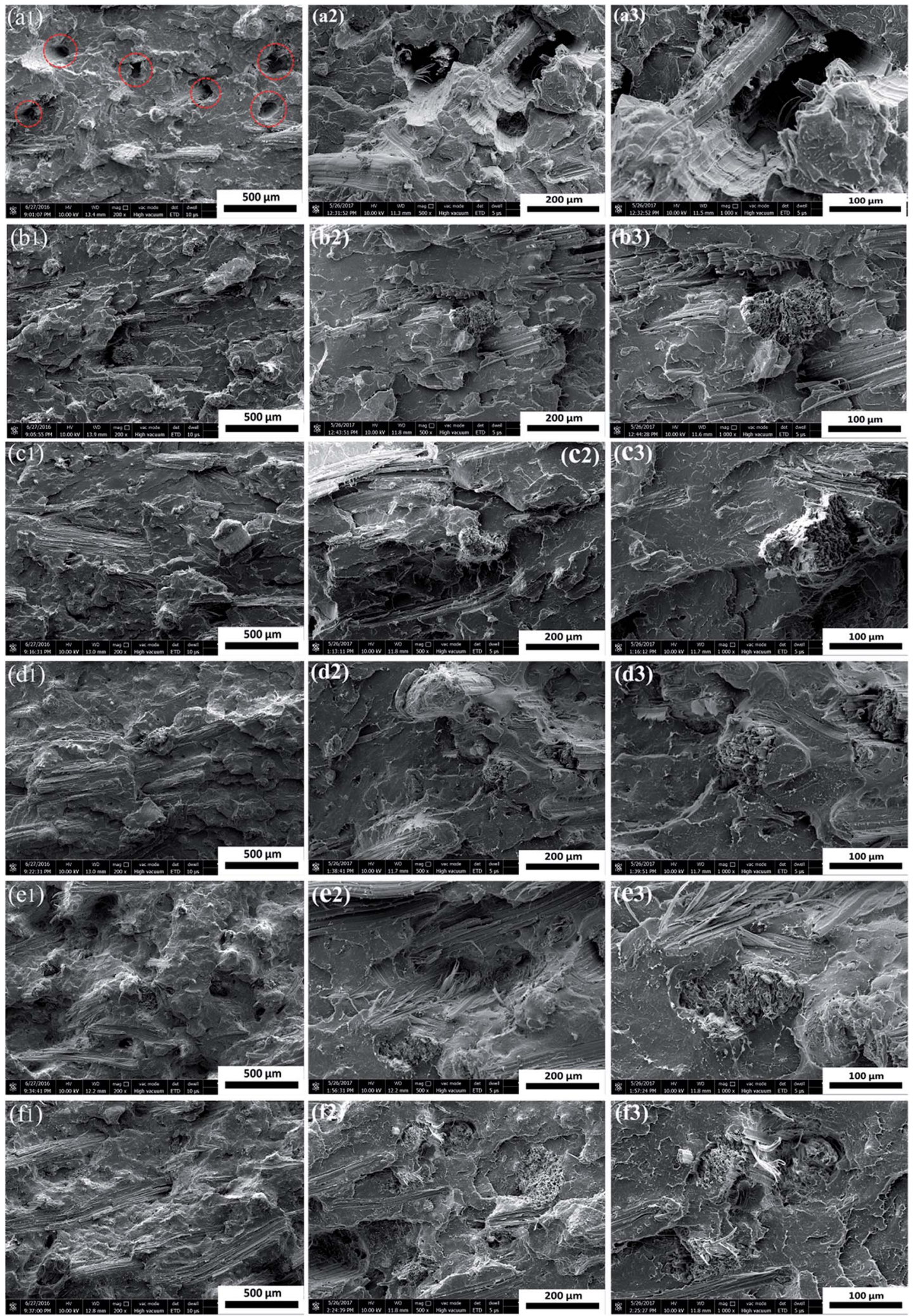

Fig. 1 The impact fracture surfaces of PLA/SF (80/20) (a1, a2, a3) and PLA/SF/EGMA composites with different EGMA content: (78/20/2) (b1, b2, b3); (76/20/4) (c1, c2, c3); (74/20/6) (d1, d2, d3); (72/20/8) (e1, e2, e3); (70/20/10) (f1, f2, f3). 1 represent 200× magnification times; 2 represent $500 \times ; 3$ represent $1000 \times$. 
between sisal fibers and PLA matrix, due to the hydrophilic nature of natural fiber while polymer matrix was hydrophobic. ${ }^{5,6}$ However, the addition of EGMA into composites during meltblending processing decreased the fibers pull-out phenomena dramatically, as observed from the Fig. 1b-f. The fibers were tightly connected with matrix and underlay the matrix, and tended to be broken and torn up in composites. The similar phenomena were observed in the tensile fracture surfaces of PLA/SF and PLA/SF/EGMA composites with different EGMA content (Fig. 2). With addition of EGMA, more sisal fibers were broken and torn up in the tensile fracture surfaces. These results reflected that the presence of EGMA improved the interfacial adhesion between the sisal fibers and PLA matrix, thus increased the stress transferability from polymer matrix to fibers in composites, therefore more fibers were fractured rather than been pulled out.
Fig. 3 displays the fibers surface morphology on the impact fracture surfaces of PLA/SF and PLA/SF/EGMA composites. For PLA/SF/EGMA composites, it was observed that some polymer matrix resin adhered to the fibers surface. Furthermore, the adhered resin exhibited obvious elasto-plastic deformation, indicating that it was EGMA, a kind of ternary copolymer elastomer. These phenomena were not observed in the PLA/SF composites, for which the fibers on the fracture surfaces nearly keep the original morphology and little PLA matrix adhered to the fibers surface, because of the poor interfacial adhesion between fibers and PLA matrix. Fig. 4 shows the high magnification impact fractured surfaces within resin part of the PLA/EGMA blends and PLA/SF/EGMA composites with $6 \mathrm{wt} \%$ and $10 \mathrm{wt} \%$ EGMA content. For PLA/EGMA blends, the fracture surface was rougher than that of PLA/SF/EGMA composites (Fig. $4 \mathrm{a}$ and b). It could be observed from Fig. $4 \mathrm{c}$ and $\mathrm{d}$ that the
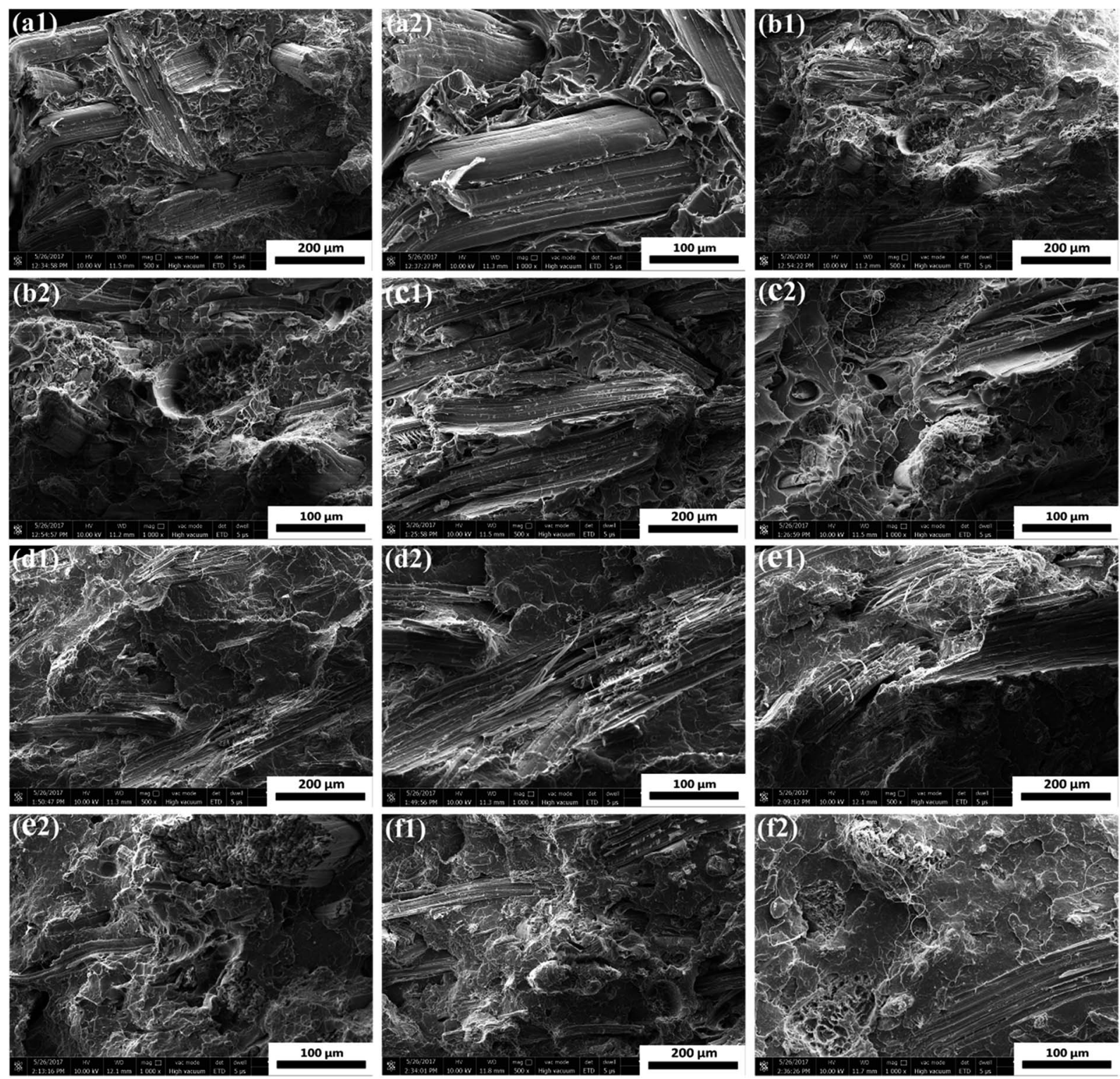

Fig. 2 The tensile fracture surfaces of PLA/SF (80/20) (a1, a2) and PLA/SF/EGMA composites with different EGMA content: (78/20/2) (b1, b2); (76/ 20/4) (c1, c2); (74/20/6) (d1, d2); (72/20/8) (e1, e2); (70/20/10) (f1, f2). 1 represent 500x; 2 represent 1000x. 

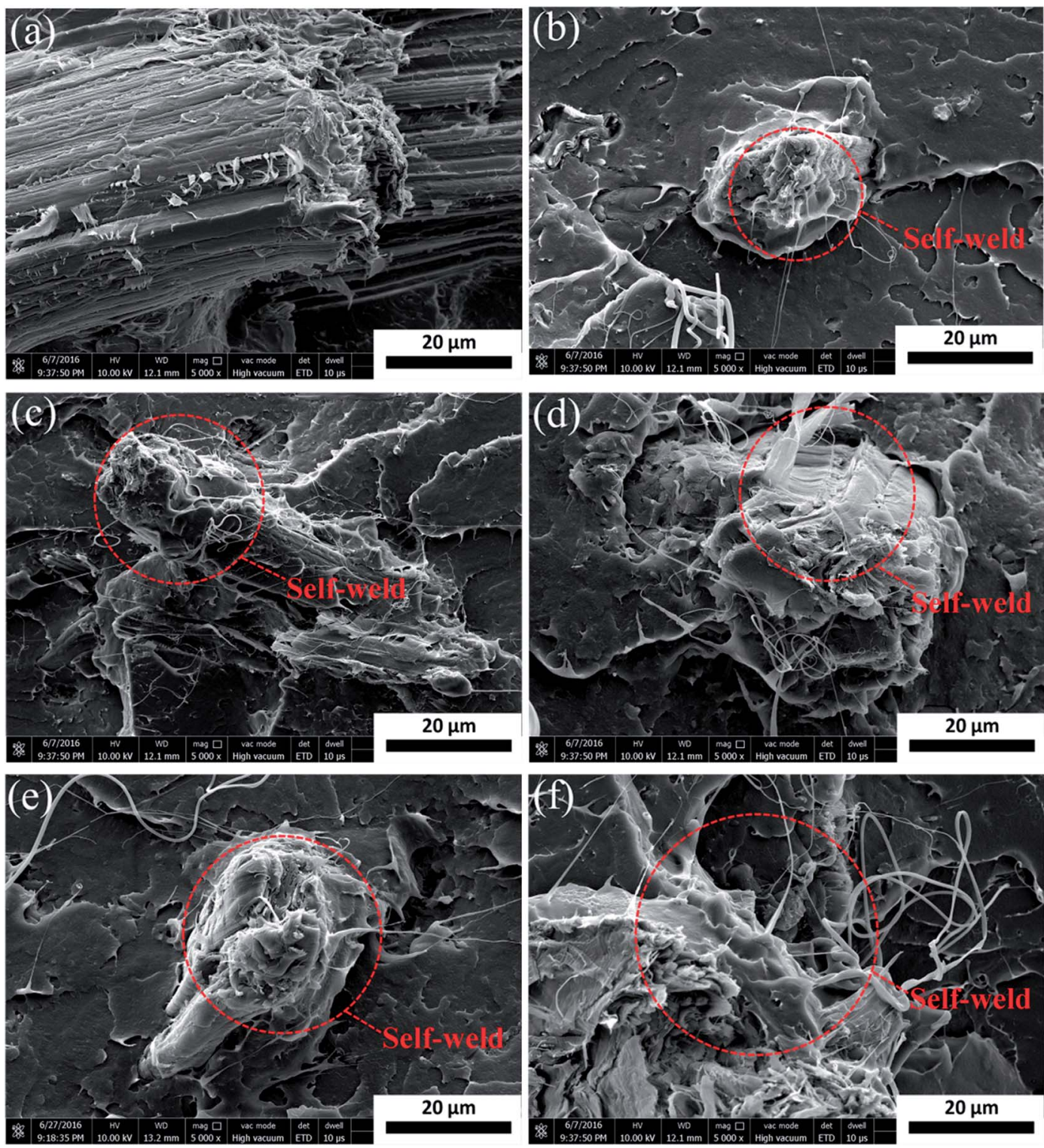

Fig. 3 Fibers surface morphology on the impact fracture surfaces of PLA/SF (80/20) (a) and PLA/SF/EGMA composites (78/20/2) (b); (76/20/4) (c); (74/20/6) (d); (72/20/8) (e); (70/20/10) (f).

EGMA phase dispersed in the PLA continuous phase, exhibited a typical "sea-island" phase structure. Meanwhile, more obvious elasto-plastic deformation of EGMA phase occurred in PLA/ EGMA blends than that of PLA/SF/EGMA composites especially in the composites with 6 wt\% EGMA content. These phenomena reflected the distribution of EGMA on fracture surface. For PLA/SF/EGMA composites, lesser EGMA was found on fracture surface within the resin part than that of PLA/EGMA blends. It was deduced that the EGMA phase in PLA/SF/EGMA composites tended to be enriched on the fibers surface. Further phase morphological observation by using TEM was performed for PLA/SF/EGMA composites and PLA/EGMA blends with 10 wt\% EGMA content (Fig. 5). The "sea-island" phase structure of PLA/EGMA blends was confirmed in Fig. $5 \mathrm{a} 1$ and a2. The fibrillated sisal fibers were observed in Fig. 5b1 and b2, and part of the EGMA phase tended to be enriched on the fibers surface. Fu et al. found that the poly(ether)urethane had stronger interaction with carbon fibers compared with PLA and it played a role of "solder" to weld the carbon fibers into a more perfect network during their investigation of incorporating poly(ether)urethane into polylactide/carbon fiber composites. ${ }^{21}$ The similar phase morphology, so-called self-weld fiber structure, ${ }^{22,23}$ was obtained in this study for the PLA/SF/EGMA composites via in situ reaction processing. Part of the soft EGMA phase enriched on the sisal fiber surface, and welded the sisal fibers to PLA matrix.

The interfacial reaction between PLA and poly(ethyleneglycidyl methacrylate) could dramatically improve the toughness of PLA, which was based on the reaction of end group of PLA molecular chain and the glycidyl methacrylate structure 

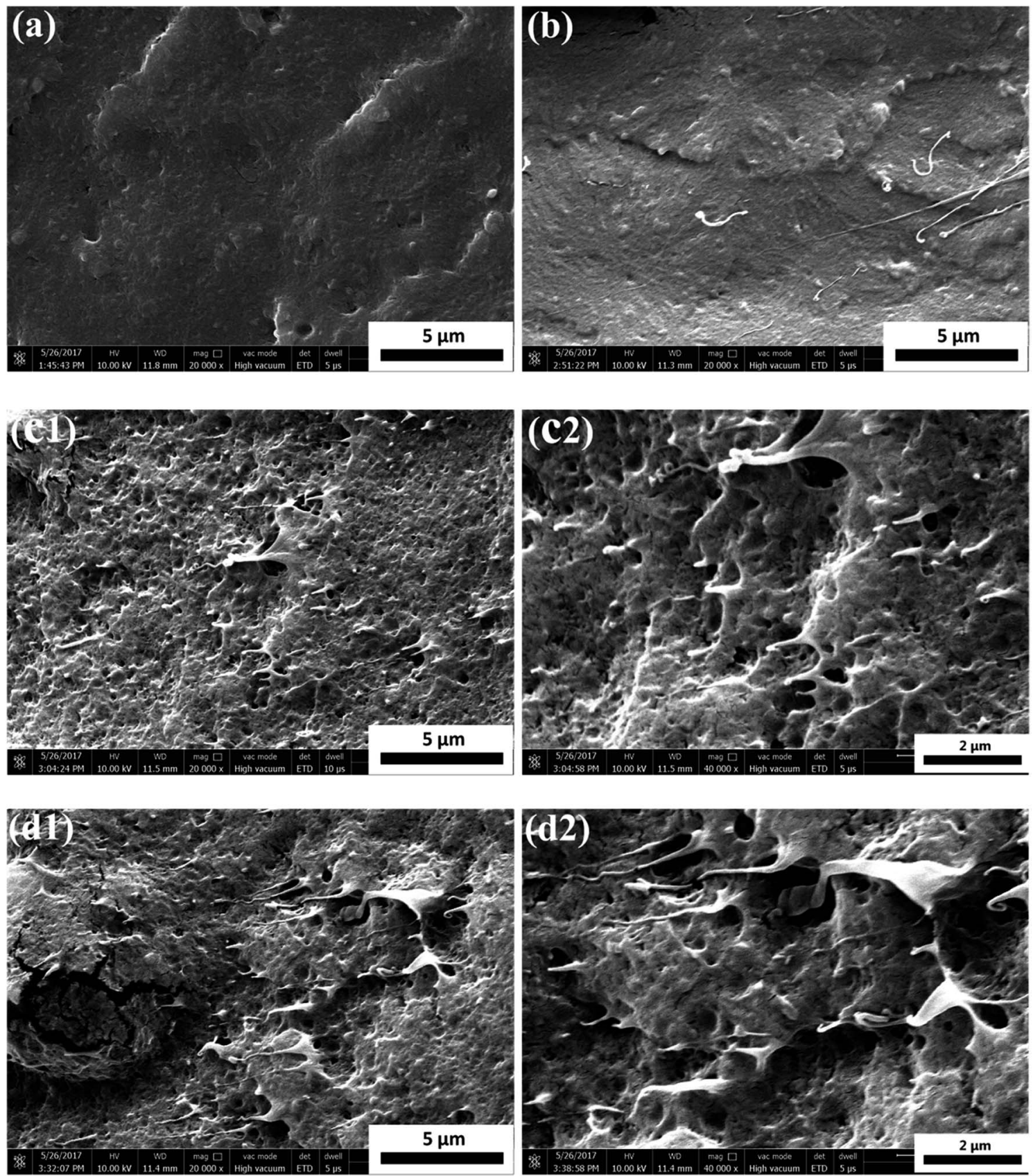

Fig. 4 High magnification SEM micrographs of impact fractured surfaces of PLA/SF/EGMA composites with different EGMA content: (74/20/6) (a), (70/20/10) (b); and PLA/EGMA blends: with different EGMA content (94/6) (c1, c2), (90/10) (d1, d2).

unit in the copolymer. ${ }^{17-20}$ In this study, the incorporating of EGMA into PLA/SF composites was considered to have two effects, improving the toughness of composites and enhancing interfacial compatibility between sisal fibers and PLA matrix via in situ reaction. The interfacial compatibilization between PLA and sisal fibers via in situ reaction with EGMA during the meltblending processing was illustrated in Fig. 6. The hydroxyl in nature fiber surface and the end group of PLA molecular chain, hydroxyl or carboxyl, could react with the epoxy group in ethylene/methyl acrylate/glycidyl methacrylate terpolymer via nucleophilic substitution. It implied that the EGMA played a role of "solder" between the fibers and matrix and so improved interfacial adhesion of the composites.

\subsection{The FTIR analysis of extracted SF}

To further prove the reaction of bonding EGMA and PLA molecular chain onto the fiber surface, Fig. 7 shows the FTIR spectra of the raw SF and extracted SF from PLA/SF and PLA/SF/ EGMA composites. The peak at $1730 \mathrm{~cm}^{-1}$ stands for the carbonyl $(\mathrm{C}=\mathrm{O})$ stretching vibration peak. This characteristic peak was not observed in raw SF, however it was found that the intensity of this $1730 \mathrm{~cm}^{-1}$ peak enhanced with addition of the 

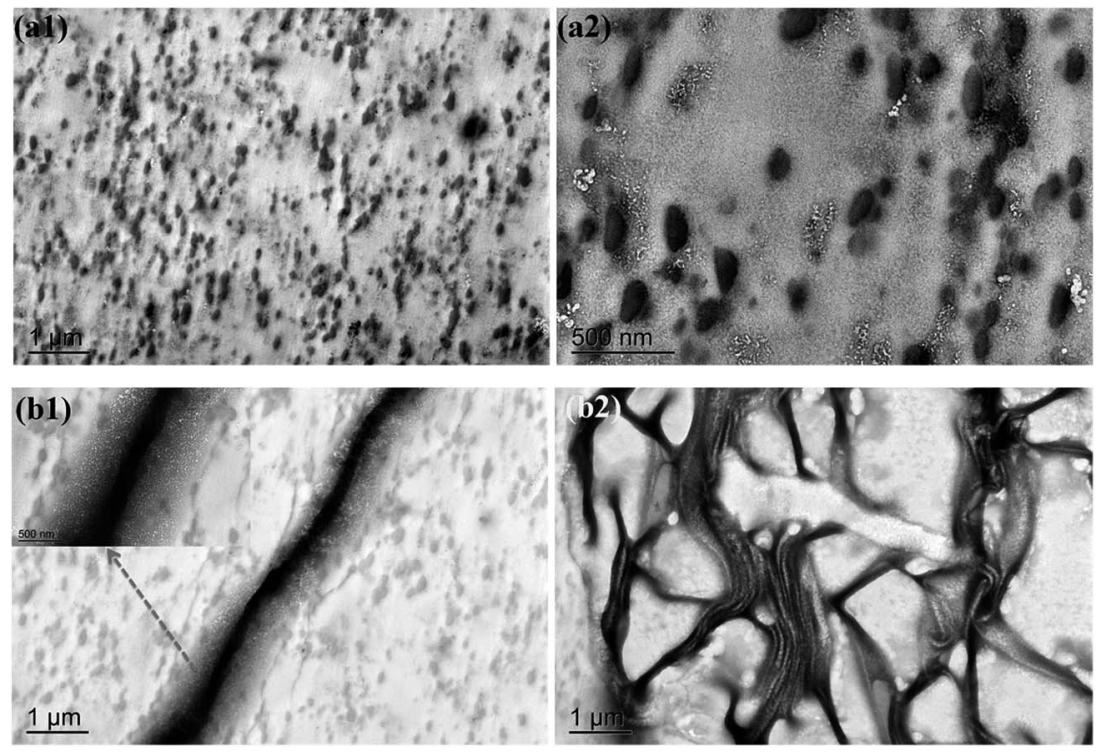

Fig. 5 TEM micrographs of PLA/EGMA blends (90/10) (a1, a2) and PLA/SF/EGMA composites (70/20/10) (b1, b2) with 10 wt\% EGMA content.

EGMA, which reflected the bonding of PLA molecular chain and EGMA to the sisal fibers during the melt-blending processing.

\subsection{Thermal behaviors}

The thermal behaviors of PLA/SF/EGMA composites and PLA/ EGMA blends with different EGMA content were investigated using DSC. Fig. 8a shows the non-isothermal crystallization behavior of PLA/SF/EGMA composites at the second heating scan with a rate of $10{ }^{\circ} \mathrm{C} \mathrm{min}^{-1}$. Cold crystallization peaks were observed and the crystallization temperatures $\left(T_{\mathrm{cc}}\right)$ were 111.7 ${ }^{\circ} \mathrm{C}$ and $117.2^{\circ} \mathrm{C}, 113.6{ }^{\circ} \mathrm{C}, 115.0{ }^{\circ} \mathrm{C}, 114.4{ }^{\circ} \mathrm{C}, 115.2{ }^{\circ} \mathrm{C}$ for the PLA/SF and PLA/SF/EGMA composites with $2 \mathrm{wt} \%, 4 \mathrm{wt} \%, 6$ wt $\%, 8$ wt $\%$ and 10 wt $\%$ EGMA, respectively (Table 2). The incorporating of EGMA increased the crystallization temperatures of PLA/SF composites. It reflected a less or harder molecular chain mobility of PLA, ${ }^{24}$ which could be ascribed to

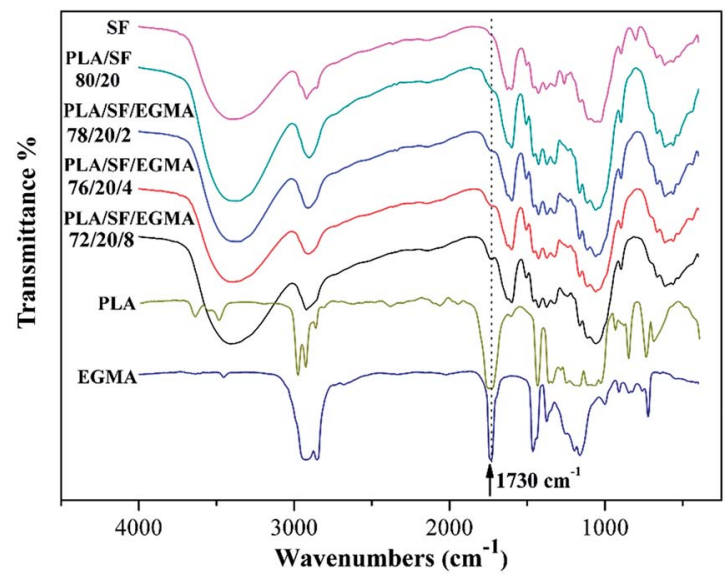

Fig. 7 The FTIR spectra of raw SF, extracted SF from the composites, PLA and EGMA resin.

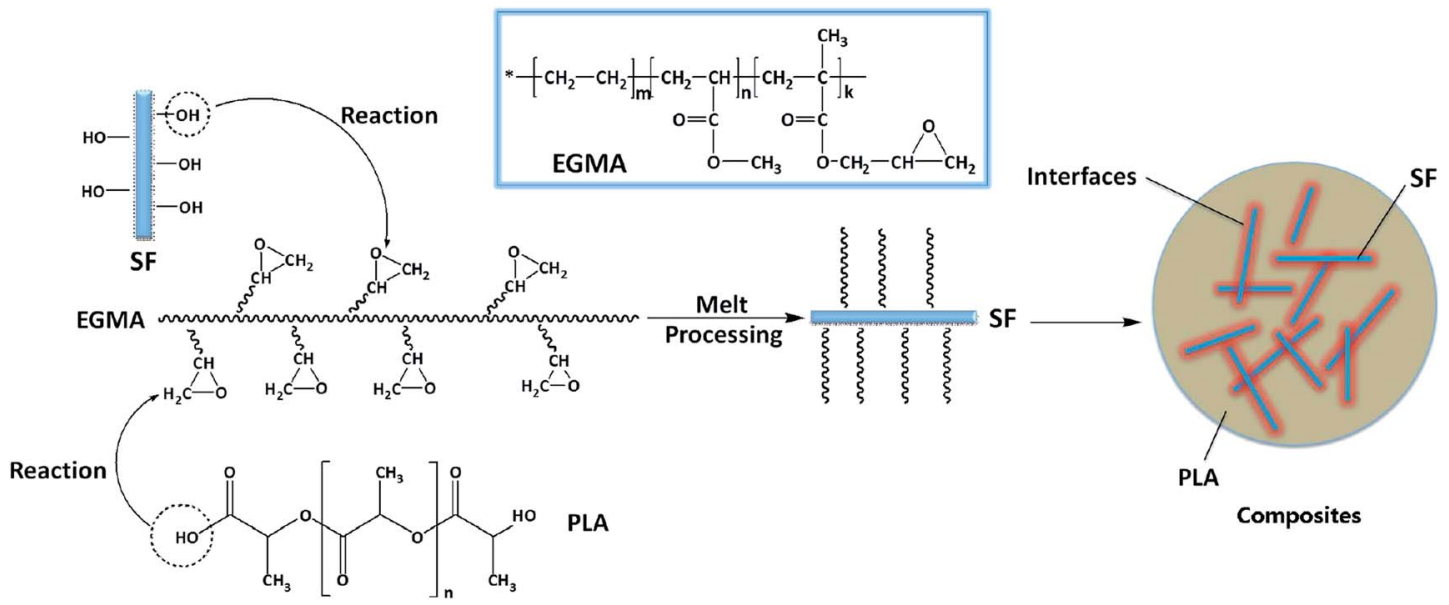

Fig. 6 Illustration of interfacial compatibilization between PLA and SF via in situ reaction with EGMA during the melt-blending processing. 

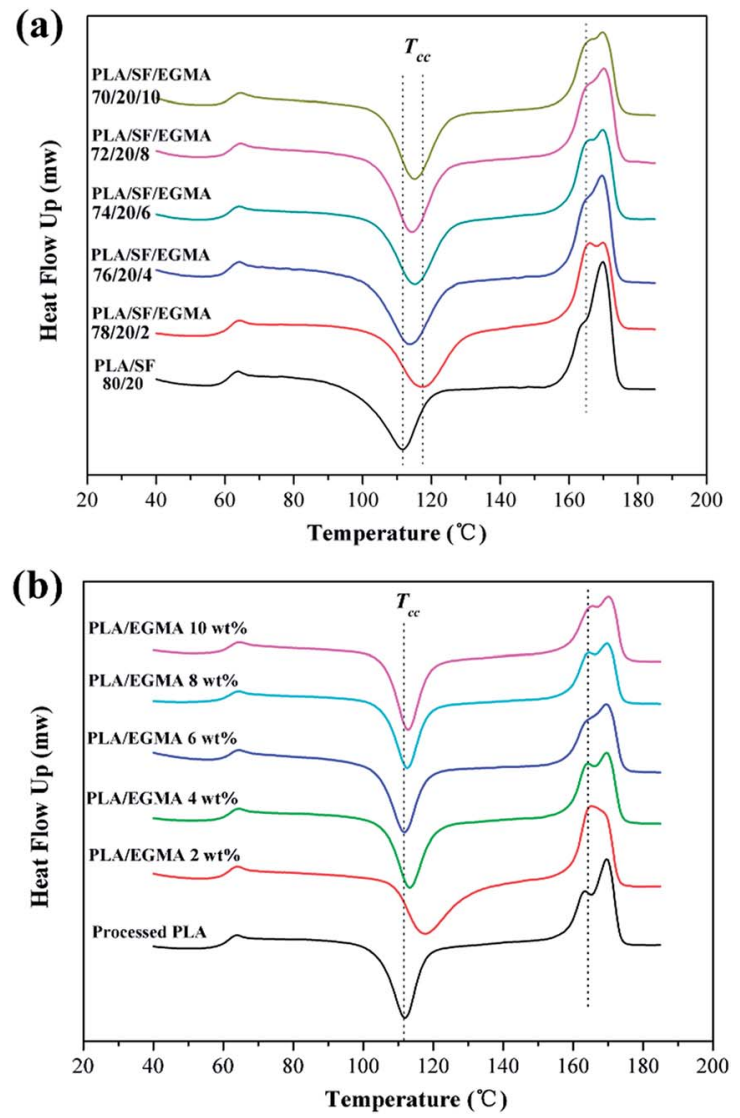

Fig. 8 DSC thermograms of PLA/SF/EGMA composites (a) and PLA/ EGMA blending (b) with different EGMA content at the second heating scan with a rate of $10{ }^{\circ} \mathrm{C} \mathrm{min}^{-1}$.

the interfacial reaction of PLA and SF with EGMA. The interfacial compatibilization between PLA and SF via reaction with EGMA restricted the molecular chain movement of PLA. At the same time, compared with the PLA/SF/EGMA composites with 2 wt\% EGMA, the crystallization temperatures decreased with more EGMA addition due to the plasticizing effect of EGMA toward PLA. Fig. 8b shows the DSC thermograms of PLA/EGMA blending with different EGMA content. The cold crystallization temperatures were $111.7{ }^{\circ} \mathrm{C}$ and $117.6{ }^{\circ} \mathrm{C}, 113.4{ }^{\circ} \mathrm{C}, 111.8{ }^{\circ} \mathrm{C}$, 112.1 ${ }^{\circ} \mathrm{C}, 112.3{ }^{\circ} \mathrm{C}$ for processed PLA and PLA/EGMA blends with 2 wt $\%, 4$ wt $\%, 6$ wt $\%, 8$ wt $\%$ and 10 wt $\%$ EGMA content, respectively (Table 2). Compared with the PLA/SF/EGMA

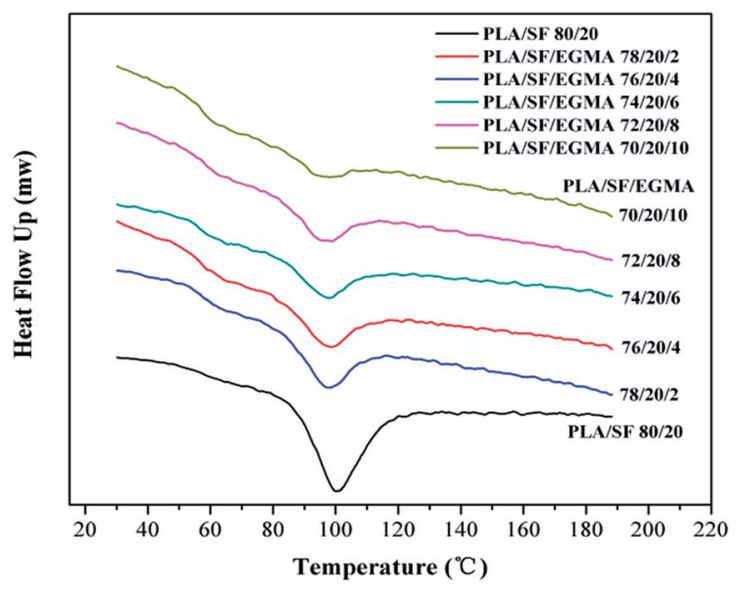

Fig. 9 DSC thermograms of PLA/SF/EGMA composites with different EGMA additions at cooling rate of $5{ }^{\circ} \mathrm{C} \mathrm{min}^{-1}$.

composites, the similar phenomena occurred in the PLA/ EGMA blends. With 2 wt\% EGMA addition, the $T_{\text {cc }}$ was obviously improved and then was prone to decrease with more EGMA addition. While behaving differently with PLA/SF/EGMA composites, the addition of EGMA at $6 \mathrm{wt} \%, 8 \mathrm{wt} \%$ and $10 \mathrm{wt} \%$ affected slightly on the $T_{\text {cc }}$ of PLA/EGMA blends compared with that of PLA, indicating that the presence of sisal fibers enhanced the interfacial reaction, thus more PLA molecular chain movement was restricted.

A shoulder peak was observed to the left of melting endothermal peak of the PLA and the composites. This phenomenon can be attributed to some poor crystalline regions with different crystalline structures formed within PLA. ${ }^{25,26}$ Furthermore, the shoulder endothermal peak was enhanced with the addition of EGMA, which demonstrated the presence of EGMA facilitated the formation of crystalline corresponding to the low $T_{\mathrm{m}}$ peak in the PLA and PLA/SF composites system. In terms of previous analysis, the presence of EGMA restricted the molecular chain movement of PLA via interfacial reaction, resulting in more poor crystalline regions formed within PLA.

Fig. 9 shows the DSC thermograms of PLA/SF/EGMA composites with different EGMA addition at cooling rate of $5{ }^{\circ} \mathrm{C} \min ^{-1}$. It was observed that the crystallization exothermal peak was dramatically weakened by incorporating of EGMA (Table 3). During the cooling stage, the mobility of PLA chain segment is significant for crystal growth. In terms of previous

Table 2 The cold crystallization temperatures $\left(T_{c c}\right)$ for PLA/SF/EGMA composites and PLA/EGMA blends with different EGMA content

\begin{tabular}{llllll}
\hline Composites & $\begin{array}{l}\text { PLA/SF } \\
80 / 20\end{array}$ & $\begin{array}{l}\text { PLA/SF/EGMA } \\
78 / 20 / 2\end{array}$ & $\begin{array}{l}\text { PLA/SF/EGMA } \\
76 / 20 / 4\end{array}$ & $\begin{array}{l}\text { PLA/SF/EGMA } \\
74 / 20 / 6\end{array}$ & $\begin{array}{l}\text { PLA/SF/EGMA } \\
72 / 20 / 8\end{array}$ \\
\hline$T_{\text {cc }}\left({ }^{\circ} \mathrm{C}\right)$ & 111.7 & 117.2 & 113.6 & 115.0 & 114.4 \\
\hline \multirow{2}{*}{ Blends } & PLA & $\begin{array}{l}\text { PLA/EGMA } 2 \\
\text { wt } \%\end{array}$ & $\begin{array}{l}\text { PLA/EGMA } 4 \\
\text { wt } \%\end{array}$ & $\begin{array}{l}\text { PLA/EGMA } 6 \\
\text { wt } \%\end{array}$ & $\begin{array}{l}\text { PLA/EGMA } 8 \\
\text { wt } \%\end{array}$ \\
\hline$T_{\text {cc }}\left({ }^{\circ} \mathrm{C}\right)$ & 111.7 & 117.6 & 113.4 & 111.8 & $\begin{array}{l}\text { PLA/EGMA 10 } \\
\text { wt } \%\end{array}$ \\
\hline
\end{tabular}


Table 3 The crystallization exothermal peak of PLA/SF/EGMA composites at cooling rate of $5{ }^{\circ} \mathrm{C} \min ^{-1}$

\begin{tabular}{llllll}
\hline & & PLA/SF/EGMA & PLA/SF/EGMA & PLA/SF/EGMA & PLA/SF/EGMA \\
Composites & PLA/SF 80/20 & $78 / 20 / 2$ & $\begin{array}{l}\text { PLA/SF/EGMA } \\
70 / 20 / 10\end{array}$ \\
\hline Exothermal peak $\left(\mathrm{J} \mathrm{g}^{-1}\right)$ & \multirow{2}{*}{19.5} & 9.05 & 8.81 & 6.57 & 5.91 \\
\end{tabular}
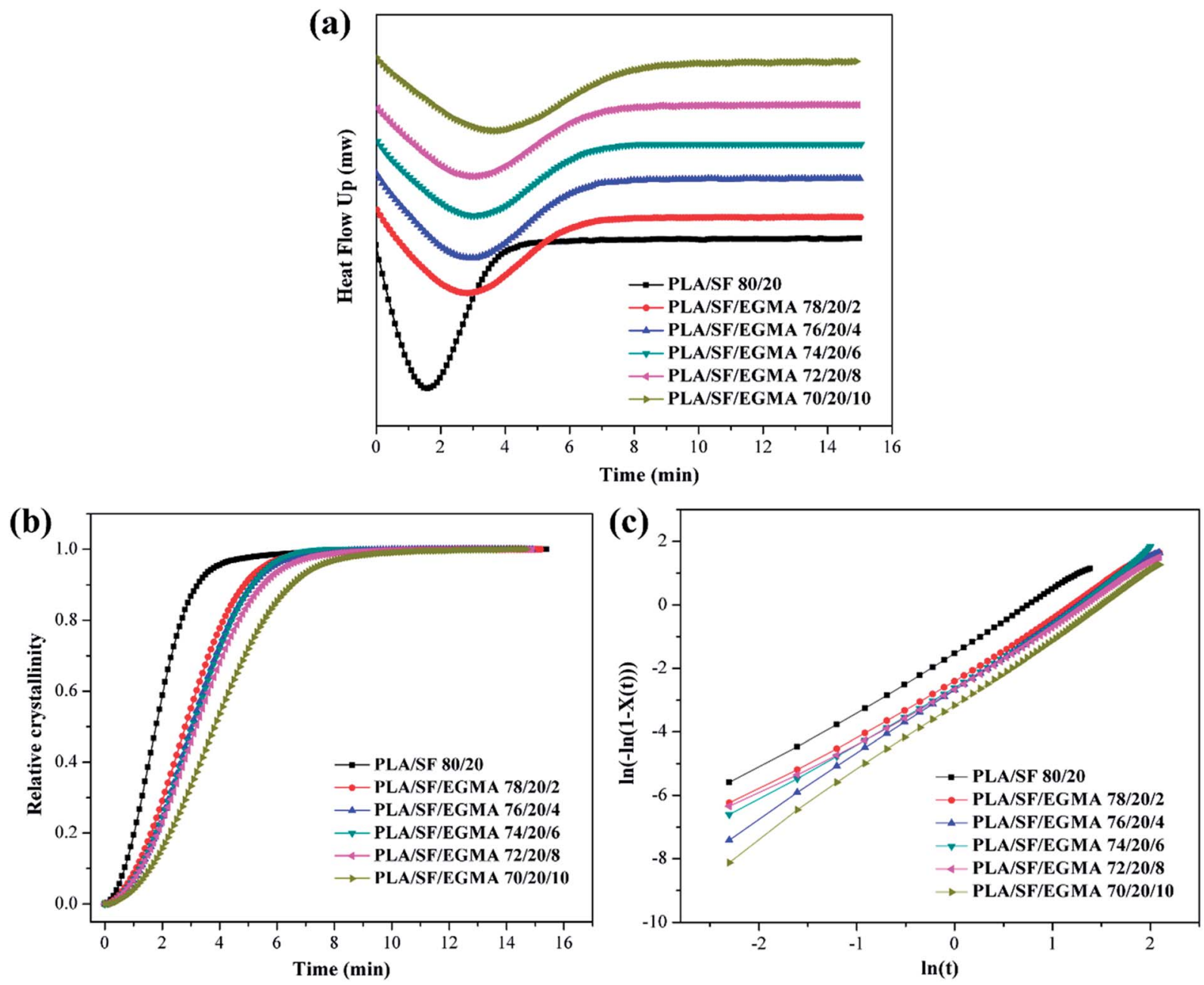

Fig. 10 Isothermal crystallization of PLA/SF/EGMA composites: DSC thermograms (a), relative crystallinity (b) and Avrami plots (c).

analysis, the mobility of PLA molecular chain was restricted because of improved interfacial interaction between PLA and SF, especially the PLA near the interface. It can be deduced that with addition of EGMA the interfacial compatibilization improved, therefore part of the PLA molecular chain was restricted and not participated in the crystallization during cooling, resulting in reduction of crystallization exothermal peak.

The isothermal melt crystallization of PLA/SF/EGMA composites with different EGMA addition was studied at $110{ }^{\circ} \mathrm{C}$. Fig. 10a shows the thermograms of composites annealed at $110{ }^{\circ} \mathrm{C}$. The relative crystallinity $\left(X_{t}\right)$ at crystallization time $t$ can be calculated using the following equation.

$$
X_{t}=\frac{Q_{t}}{Q_{\infty}}=\frac{\int_{0}^{t}(\mathrm{~d} H / \mathrm{d} t) \mathrm{d} t}{\int_{0}^{\infty}(\mathrm{d} H / \mathrm{d} t) \mathrm{d} t}
$$

where $\mathrm{d} H / \mathrm{d} t$ is the rate of heat flow, and $Q_{\infty}$ and $Q_{t}$ are heat generated at infinite time and at time $t$. Fig. $10 \mathrm{~b}$ presents the change of relative crystallinity as crystallization time for composites. The crystallization time increased with more addition of EGMA. The kinetic analysis of isothermal crystallization can be performed by using the well-known Avrami equation. ${ }^{27,28}$

$$
X(t)=1-\exp \left(-k t^{n}\right)
$$


Table 4 Isothermal crystallization half time and kinetic parameters of PLA/SF composites with and without EGMA addition

\begin{tabular}{llll}
\hline Samples & $n$ & $k\left(\mathrm{~min}^{-n}\right)$ & $t_{1 / 2}(\mathrm{~min})$ \\
\hline PLA/SF 80/20 wt\% & 1.91 & 0.234 & 1.77 \\
PLA/SF/EGMA 78/20/2 $\mathrm{wt} \%$ & 1.90 & 0.101 & 2.77 \\
PLA/SF/EGMA 76/20/4 wt\% & 2.10 & 0.0706 & 2.97 \\
PLA/SF/EGMA 74/20/6 wt\% & 1.94 & 0.0809 & 3.03 \\
PLA/SF/EGMA 72/20/8 wt\% & 1.89 & 0.0791 & 3.16 \\
PLA/SF/EGMA 70/20/10 wt\% & 2.11 & 0.0420 & 3.77
\end{tabular}

where $X(t)$ is the relative crystallinity, $k$ is the crystallization rate constant and $n$ is the Avrami exponent reflecting the mechanisms of crystal nucleation and growth, and the following equation can be deduced from eqn (2)

$$
\ln \{-\ln [1-X(t)]\}=\ln k+n \ln t
$$

By plotting $\ln [-\ln (1-X(t))]$ versus $\ln (t)$, the Avrami exponent, $n$, and crystallization rate constant, $k$, were determined.

Fig. 10c demonstrates the Avrami plots, from which the $n$ and $k$ can be obtained as Avrami parameters. The obtained Avrami parameters are summarized in Table 4. It was found that as increase of EGMA addition, the $n$ value varies from 1.89 to 2.11 , indicating the crystals tend to grow in two dimensional for composites. Compared with PLA/SF composites, the $k$ value of PLA/SF/EGMA composites decreased with addition of EGMA. The crystallization rate constant of $k$ associated with nucleation and growth, while it is not properly to compare the crystallization rate of composites from the $k$ values directly, for the unit of $k$ is $\min ^{-n}$ and the $n$ values are not constant for different samples. ${ }^{29}$ Based on the Avrami parameters of $n$ and $k$, the crystallization half-time $t_{1 / 2}$, reflecting the crystallization rate, can be calculated from the following equation.

$$
t_{1 / 2}=\left(\frac{\ln 2}{k}\right)^{1 / n}
$$

The obtained crystallization half-time was 1.77 minutes for PLA/SF composites and 2.77, 2.97, 3.03, 3.16, 3.77 minutes for PLA/SF/EGMA composites with 2 wt $\%, 4$ wt $\%, 6$ wt $\%, 8$ wt $\%$ and $10 \mathrm{wt} \%$ EGMA content, respectively (Table 4). It demonstrated that the PLA/SF/EGMA composites exhibited a lower crystallization rate compared with that of PLA/SF composites. The explanation for this would be that the decreased mobility of the PLA chain segments restricted its alignment into crystalline regions, thus reduce the crystallization rate of composites.

\subsection{Rheological characterization}

The rheological behaviors of polymers or polymer composites are very sensitive to the change of microstructure, which attracted fundamental interest in this study. Small amplitude oscillatory frequency sweeps were executed to analyze the effect of incorporated EGMA on the rheological behavior of PLA/SF

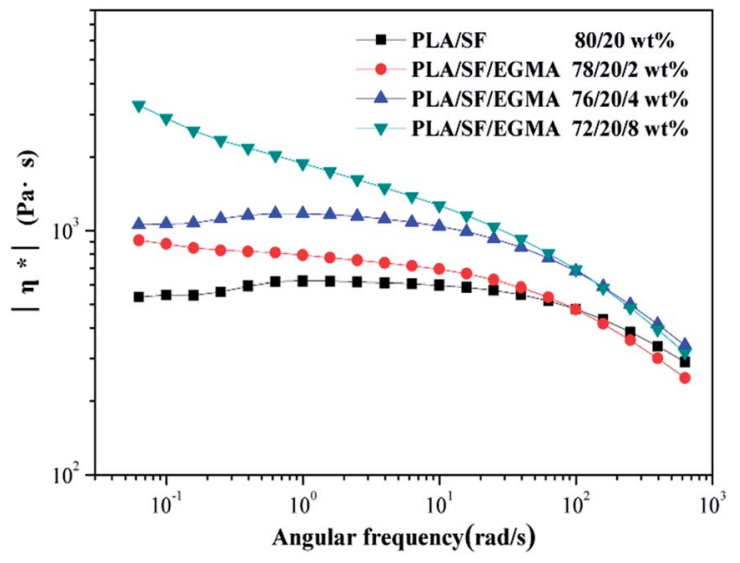

Fig. 11 Changes of complex viscosity as functions of angular frequency for PLA/SF composites with different EGMA content.

composites and so to estimate the microstructure change of composites.

Fig. 11 presents the changes of complex viscosity, $\left|\eta^{*}\right|$, as a function of angular frequency for the PLA/SF composites with different EGMA content. It can be seen that at low angular frequency the complex viscosity of composites increased with the increasing amount of EGMA. And, two types of frequency dependence of complex viscosity occurred for the composites. For the PLA/SF and PLA/SF/EGMA composites with low EGMA content, that were $2 \mathrm{wt} \%$ and $4 \mathrm{wt} \%$, the complex viscosity nearly remained constant at the low angular frequency range, and then decreased with further increasing of angular frequency, which exhibited a transition from the Newtonian plateau to power law regime at the inflection point. While, the Newtonian shear flow behavior was not observed for PLA/SF/ EGMA composites with $8 \mathrm{wt} \%$ content. And, it can be seen that the shear-thinning behavior occurred in the whole experimental angular frequency range, which implied that the composites with high EGMA content followed more obviously power law regime. ${ }^{30}$ The shear-thinning behavior was enhanced for composites with increasing content of EGMA. These phenomena can be ascribed to the improved interfacial interaction between fibers and matrix via in situ reaction of PLA and SF with EGMA during the melt processing, which also reduced the chain mobility of PLA, and therefore the dynamic viscosity was enhanced. At the same time more chain entanglement might form in composites as the EGMA content increased, resulting in enhanced shear-thinning behavior.

Fig. 12 displays the changes of storage modulus, $G^{\prime}$, and loss modulus, $G^{\prime \prime}$, as functions of angular frequency, $\omega$, for the PLA/ SF/EGMA composites with different EGMA addition. It can be seen that as increasing of EGMA content both of the storage modulus and loss modulus of composites were improved, especially the composites with 8 wt\% EGMA content. For linear polymer, the storage modulus and loss modulus are well-known angular frequency dependence, that are $G^{\prime} \propto \omega^{2}$ and $G^{\prime \prime} \propto \omega$, in the terminal angular frequency region, for which mainly the longest relaxation times contribute to the viscoelastic behavior. As shown in Table 5, the slopes of $G^{\prime}$ at the low angular 

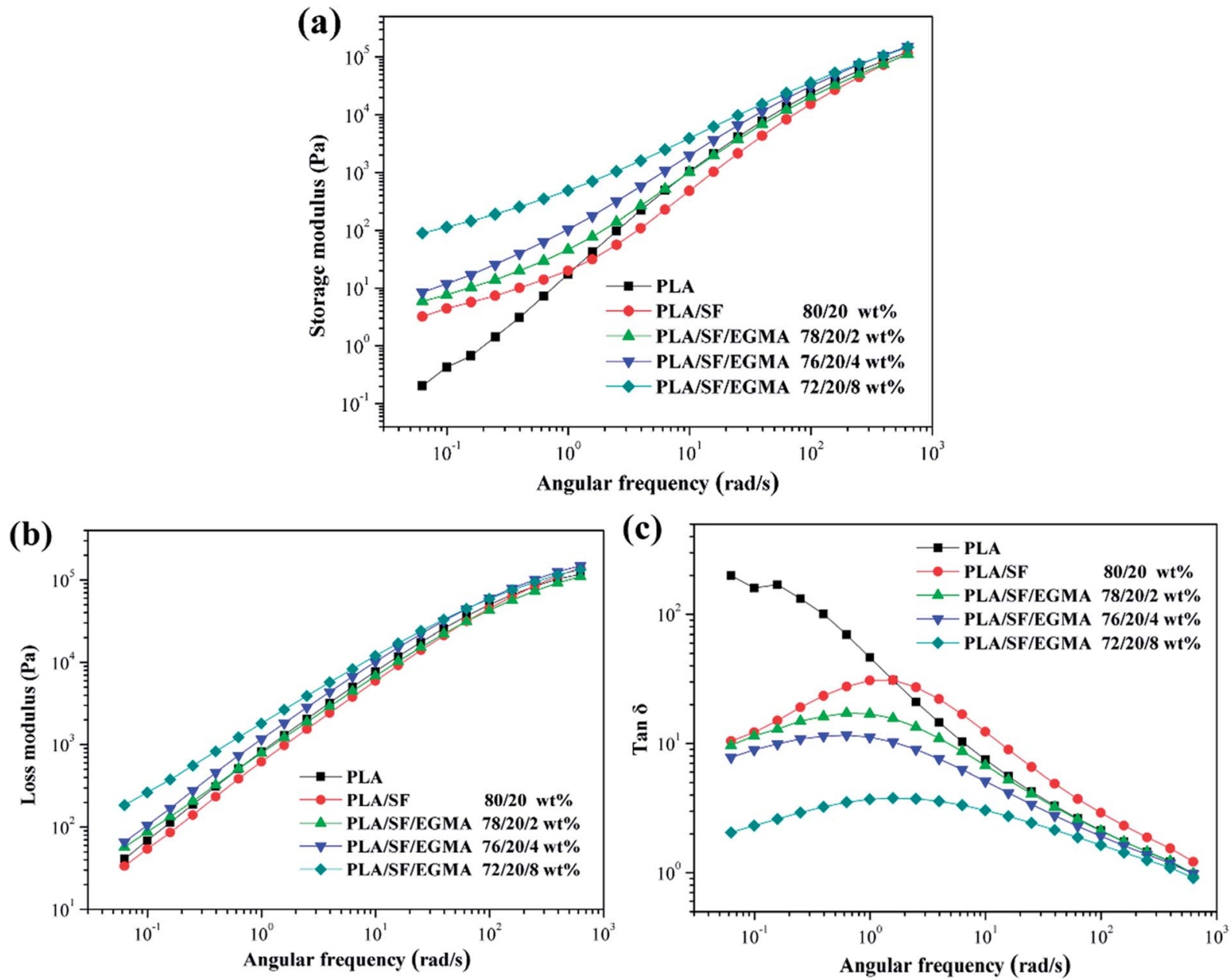

Fig. 12 Changes of storage modulus (a), loss modulus (b) and $\tan \delta$ (c) as functions of angular frequency for PLA/SF/EGMA composites with 20 wt\% SF content and different EGMA addition.

Table 5 The slope of $G^{\prime}$ and $G^{\prime \prime}$ at the low angular frequency region

\begin{tabular}{|c|c|c|c|c|c|}
\hline $\begin{array}{l}\text { Terminal } \\
\text { slope }\end{array}$ & PLA & $\begin{array}{l}\mathrm{PLA} / \mathrm{SF} \\
80 / 20\end{array}$ & $\begin{array}{l}\text { PLA/SF/EGMA } \\
78 / 20 / 2\end{array}$ & $\begin{array}{l}\text { PLA/SF/EGMA } \\
76 / 20 / 4\end{array}$ & $\begin{array}{l}\text { PLA/SF/EGMA } \\
72 / 20 / 8\end{array}$ \\
\hline$G^{\prime}$ & 1.822 & 0.623 & 0.624 & 0.724 & 0.586 \\
\hline$G^{\prime \prime}$ & 1.055 & 1.053 & 0.944 & 1.051 & 0.812 \\
\hline
\end{tabular}

frequency region were $1.822,0.623,0.624,0.724$ and 0.586 for the processed PLA, PLA/SF composites and PLA/SF/EGMA composites with $2 \mathrm{wt} \%, 4 \mathrm{wt} \%$ and $8 \mathrm{wt} \%$, respectively. And the corresponding slopes of $G^{\prime \prime}$ at the low angular frequency region were $1.055,1.053,0.944,1.051$ and 0.812 , respectively. The slops of $G^{\prime}$ were lower than that of $G^{\prime \prime}$, which indicated a solid-like behavior of composites. ${ }^{31}$ The deviation from the ideal fluid at low angular frequency demonstrated high elasticity for PLA/SF/EGMA composites, especially the sample with high EGMA content.

The high elasticity of PLA/SF/EGMA composites can also be illustrated by loss tangent $\left(\tan \delta=G^{\prime \prime} / G^{\prime}\right.$ ). And the frequency dependence of $\tan \delta$ can be adopted to confirm the gel point of cross-linking systems. ${ }^{32,33}$ This method was widely used for polymer composites to estimate the percolation thresholds of the fillers. ${ }^{34,35}$ The changes of loss tangent, as functions of angular frequency were shown in Fig. 12c. For neat PLA, $\tan \delta$ descended with increasing angular frequency, which was a typical rheological behavior of liquid-like materials. Behaving differently, PLA/SF/EGMA composites displayed a gel-like behavior. The $\tan \delta$ decreased and showed less dependence on angular frequency. And nearly a plateau was reached in PLA/ SF/EGMA composites with $8 \mathrm{wt} \%$ EGMA content. In terms of previous analysis, the in situ interfacial reaction of PLA and SF with EGMA restricted the molecular chain movement of PLA, and sisal fibers acted as physical cross-linker. The stress relaxation of PLA molecular chain became more difficult in melt state, thus improved the elastic response of composites and the gel-like behavior occurred. The gel-like behavior of PLA/SF/ EGMA composites also indicated the formation of self-weld SF network structure, ${ }^{21}$ and this result was consistent well with Malchev' study. ${ }^{36}$ The in situ interfacial reaction of PLA/SF/ EGMA composites during melt-blending processing resulted in the enrichment of EGMA on fiber surface, which was also 
confirmed in SEM analysis, facilitating the formation of fibers network.

\subsection{Mechanical properties}

The impact strength of PLA/SF/EGMA composites with different EGMA content is shown in Fig. 13. The impact strength of composites ascended with increasing of EGMA content. The impact strength of composites with 10 wt\% EGMA was over three times more than that of PLA/SF composites. As shown in Fig. 1, the PLA/SF composite exhibited a much smoother fracture surfaces than that of PLA/SF/EGMA composites with high EGMA content, indicating a typical brittle fracture behavior of composites without EGMA addition. The elasto-plastic deformation of matrix could also be observed from Fig. 3, and some of them occurred on the fiber surface. These results contributed to occurrence of large energy dissipation, consequently improved the impact strength.

Fig. 14 presents the tensile strength and tensile modulus of PLA/SF/EGMA composites (Fig. 14a), PLA/EGMA blends (Fig. 14b) with different EGMA content. The tensile modulus of PLA/SF/EGMA composites and PLA/EGMA blends were decreased with more EGMA addition, and it was found that the tensile modulus was improved by SF composites, reflecting enhanced stiffness of PLA/SF/EGMA composites compared with that of PLA/EGMA blends. The tensile strength are 46.5 MPa, 51.9 MPa, 50.9 MPa, 49.3 MPa, 47.9 MPa and 45.3 MPa for the PLA/SF and PLA/SF/EGMA composites with $2 \mathrm{wt} \%, 4 \mathrm{wt} \%, 6$ wt $\%, 8$ wt $\%$ and 10 wt $\%$ EGMA content, respectively. The incorporating of EGMA into PLA/SF composites did not cause much decline of tensile strength. On the contrary, with the addition of 2 wt $\%$ EGMA, the tensile strength was improved from 46.5 $\mathrm{MPa}$ to $51.9 \mathrm{MPa}$. And as the EGMA content increased, the tensile strength decreased mildly. The tensile strength of the composites with $10 \mathrm{wt} \%$ EGMA still preserved as 97.4\% of the PLA/SF composites. Behaving differently, the tensile strength of PLA/EGMA blends decreased significantly with increase of EGMA content, which was consistent with the results reported in the previous studies. ${ }^{\mathbf{1 9 , 2 0}}$ The tensile strength

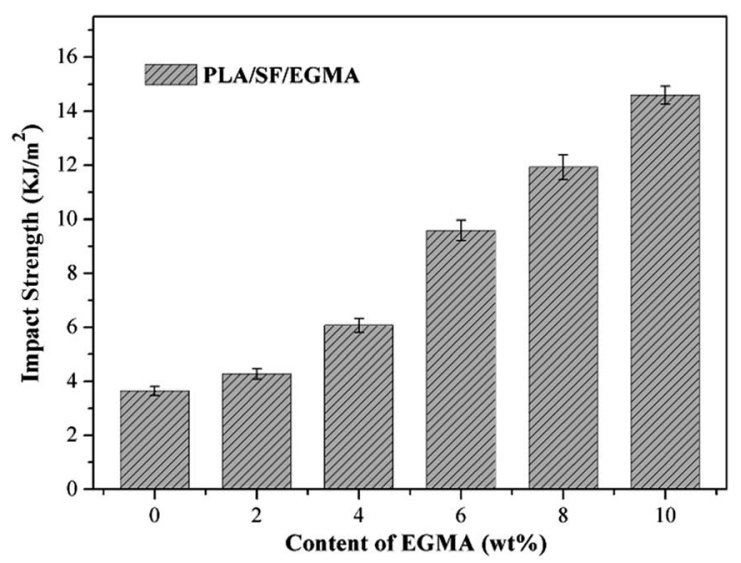

Fig. 13 Impact strength of PLA/SF/EGMA composites with different EGMA addition.
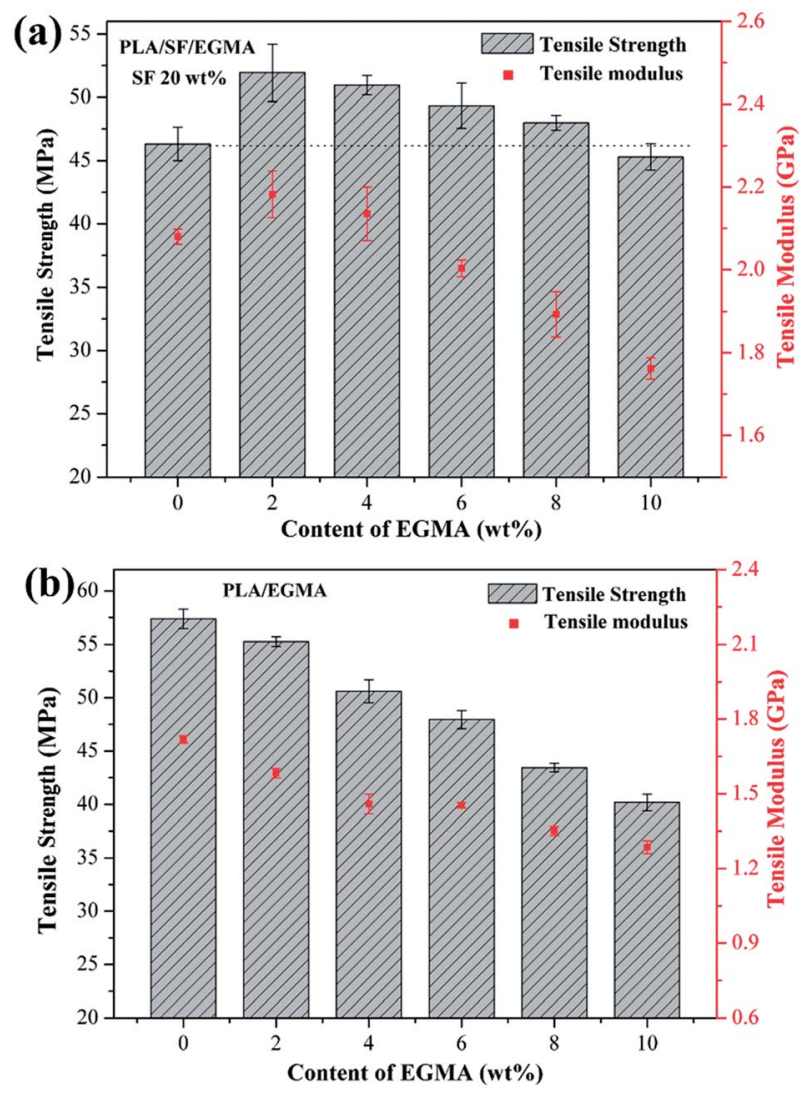

Fig. 14 Tensile strength and tensile modulus of PLA/SF/EGMA composites (a) and PLA/EGMA blends (b) with different EGMA content.

of PLA/EGMA blends with 10 wt $\%$ EGMA content preserved as $70.1 \%$ of the neat PLA. The PLA/SF/EGMA composites can preserve the tensile strength than that of PLA/EGMA composite.

The tensile strength, tensile modulus and impact strength of PLA/SF and PLA/SF/EGMA composites with different SF content and $4 \mathrm{wt} \%$ EGMA were shown in Fig. 15. The tensile modulus was improved as increase of SF content, indicating enhanced stiffness in high sisal fibers content (Fig. 15a). However, as increase of SF content, the tensile strength of PLA/SF composites decreased. This phenomenon could be ascribed to the poor interfacial adhesion between fibres and matrix. More fibers added more defect points of microstructure of composites were induced, which resulted in the stress concentration under loading conditions, and therefore the tensile strength of PLA/SF composite declined with the addition of SF. Behaving differently with PLA/SF composites, the tensile strength of PLA/SF/ EGMA composites improved as increase of SF content. Furthermore, more SF additions, more significantly enhance effect was observed. The impact strength of PLA/SF/EGMA was also enhanced, compared with that of PLA/SF composites (Fig. 15b). The results implied that PLA/SF composites were simultaneously reinforced and toughened via addition of $4 \mathrm{wt} \%$ EGMA.

The above analyses demonstrate that the presence of EGMA improved the interfacial adhesion of SF fibers with matrix via in situ interfacial reaction, and a part of the EGMA was prone to be 

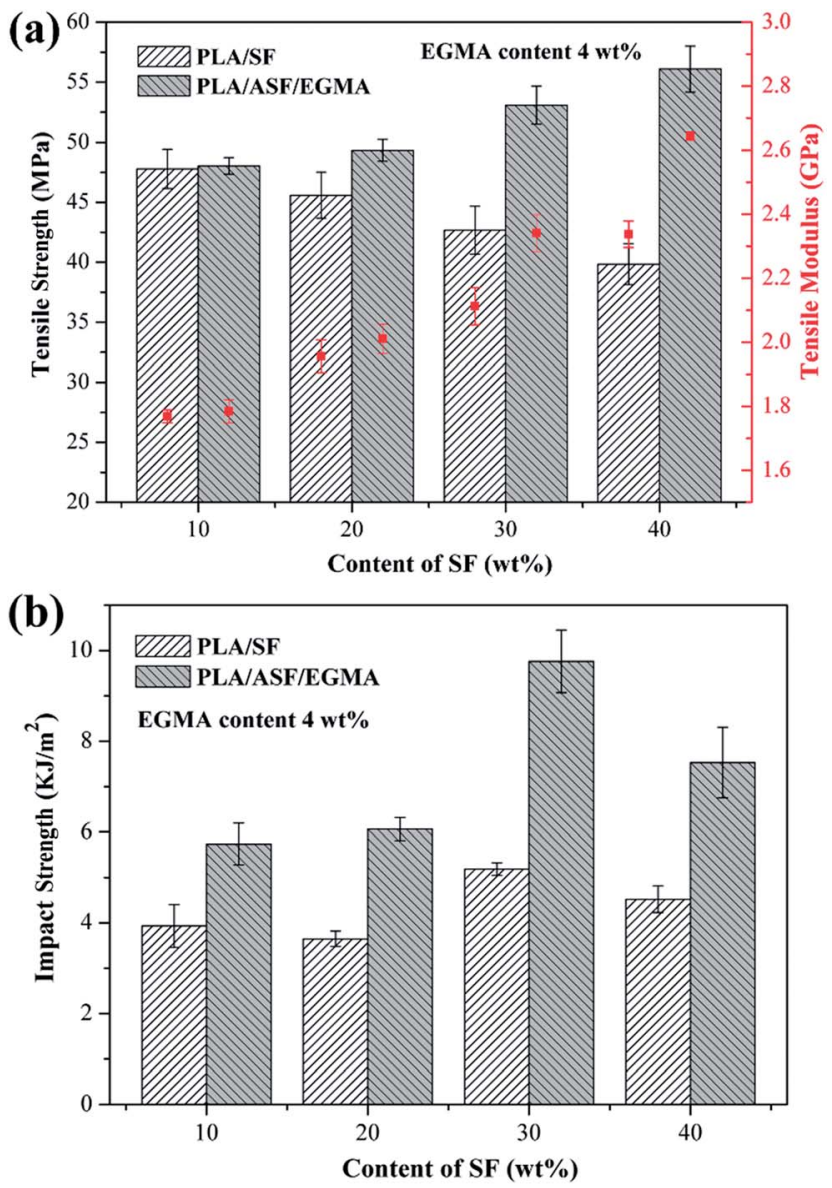

Fig. 15 Tensile strength, tensile modulus (a) and impact strength (b) of PLA/SF and PLA/SF/EGMA composites with different SF content.

enriched on the surface of SF, welding the sisal fibers to PLA matrix. Therefore a moderate interface was formed between fibers and PLA matrix, which decreased the stress concentration under loading conditions and transfer the loads from PLA matrix to SF more effectively. ${ }^{8,37,38}$ In terms of previous SEM analysis, for the composites with the presence of EGMA, the fibers were tightly connected with matrix and underlay the matrix, and many fibers were broken and torn up in fracture surface rather than pulled out, reflecting more effective of stress transfer. Therefore, the improved interfacial adhesion of sisal fibers with matrix compensated the decline of tensile strength because of the introduction of soft EGMA elastomer, and hence the tensile strength of PLA/SF/EGMA composites could be preserved. The self-weld fiber structure contributed to obtain good mechanical stiffness-toughness balanced properties.

\section{Conclusions}

In this work, a simple melt-blending method was used to fabricate polylactide/sisal fiber biocomposites with addition of an epoxy-functionalized reactive elastomer, ethylene/methyl acrylate/glycidyl methacrylate (EGMA) terpolymer. The introduction of EGMA improved the interfacial adhesion between sisal fibers and matrix via in situ reaction of PLA and SF with
EGMA during the melt-blending processing. And, it was also observed that part of EGMA tend to weld on the fiber surface, which was called self-weld fiber structure. The interfacial reaction and microstructure of composites were further investigated by FTIR characterizations, thermal and rheological analyses. DSC and dynamic rheological measurements indicated that the molecular chain mobility of PLA was restricted due to the improved interfacial interaction of composites. The incorporating of EGMA into PLA/SF composites was considered to have two effects, enhancing interfacial compatibility of sisal fibers and PLA matrix, and improving the toughness of composites. The addition of EGMA facilitated composites to obtain a good mechanical stiffness-toughness balanced property, improving the toughness of PLA/SF composites without much decline of tensile strength.

\section{Acknowledgements}

This work was financial supported by the Specialized Research Fund for the Doctoral Program of Higher Education of China (20120172130004) and National Key Basic Research Program of China (2012CB025902).

\section{References}

1 F. Ahmad, H. S. Choi and M. K. Park, A Review: Natural Fiber Composites Selection in View of Mechanical, Light Weight, and Economic Properties, Macromol. Mater. Eng., 2015, 300, 10-24.

2 K. L. Pickering, M. G. A. Efendy and T. M. Le, A review of recent developments in natural fibre composites and their mechanical performance, Composites, Part A, 2016, 83, 98112.

3 K. Oksman, M. Skrifvars and J. F. Selin, Natural fibres as reinforcement in polylactic acid (PLA) composites, Compos. Sci. Technol., 2003, 63, 1317-1324.

$4 \mathrm{~W}$. Liu, T. Xie and R. Qiu, $N$-methylol acrylamide grafting bamboo fibres and their composites, Compos. Sci. Technol., 2015, 117, 100-106.

5 X. Dai, Z. Xiong and H. Na, How does epoxidized soybean oil improve the toughness of microcrystalline cellulose filled polylactide acid composites?, Compos. Sci. Technol., 2014, 90, 9-15.

6 O. Faruk, A. K. Bledzki and H. P. Fink, Biocomposites reinforced with natural fibres: 2000-2010, Prog. Polym. Sci., 2012, 37, 1552-1596.

7 B. L. S. Sipião, L. S. Reis, R. D. L. M. Paiva, M. R. Capri and D. R. Mulinari, Lignocellulosic Polymer Composites: Processing, Characterization and Properties, Wiley, New York, 2015.

8 C. Ping, C. Lu and Y. Qi, Influence of fibre wettability on the interfacial adhesion of continuous fibre-reinforced PPESK composite, J. Appl. Polym. Sci., 2006, 102, 2544-2551.

9 M. M. Kabir, H. Wang and K. T. Lau, Chemical treatments on plant-based natural fibre reinforced polymer composites: an overview, Composites, Part B, 2012, 43, 2883-2892. 
10 T. Yu, J. Ren and S. Li, Effect of fibre surface-treatments on the properties of poly(lactic acid)/ramie composites, Composites, Part A, 2010, 41, 499-505.

11 Y. Xie, C. A. S. Hill and Z. Xiao, Silane coupling agents used for natural fibre/polymer composites: a review, Composites, Part A, 2010, 41, 806-819.

12 A. K. Bledzki, A. A. Mamun, M. Lucka-Gabor and V. S. Gutowski, The effects of acetylation on properties of flax fibre and its polypropylene composites, eXPRESS Polym. Lett., 2008, 2, 413-422.

13 B. Wang, S. Panigrahi, L. Tabil and W. Crerar, Pre-treatment of Flax Fibres for use in Rotationally Molded Biocomposites, J. Reinf. Plast. Compos., 2007, 26, 447-463.

14 M. K. Zahran and M. F. Rehan, Grafting of acrylic acid onto flax fibres using $\mathrm{Mn}(\mathrm{Iv})$-citric acid redox system, J. Appl. Polym. Sci., 2006, 102, 3028-3036.

15 S. Kalia, B. S. Kaith and I. Kaur, Pretreatments of natural fibres and their application as reinforcing material in polymer composites-a review, Polym. Eng. Sci., 2009, 49, 1253-1272.

$16 \mathrm{M}$. Zhou, Y. Li and C. He, Interfacial crystallization enhanced interfacial interaction of poly(butylene succinate)/ramie fibre biocomposites using dopamine as a modifier, Compos. Sci. Technol., 2014, 91, 22-29.

17 H. Liu, W. Song and F. Chen, Interaction of Microstructure and Interfacial Adhesion on Impact Performance of Polylactide (PLA) Ternary Blends, Macromolecules, 2011, 44, 1513-1522.

18 V. Ojijo and S. S. Ray, Super toughened biodegradable polylactide blends with non-linear copolymer interfacial architecture obtained via, facile in situ reactive compatibilization, Polymer, 2015, 80, 1-17.

19 Y. Feng, G. Zhao and J. Yin, Reactive compatibilization of high-impact poly(lactic acid)/ethylene copolymer blends catalyzed by $N, N$-dimethylstearylamine, Polym. Int., 2014, 63, 1263-1269.

$20 \mathrm{M}$. Wu, Z. Wu and K. Wang, Simultaneous the thermodynamics favorable compatibility and morphology to achieve excellent comprehensive mechanics in PLA/OBC blend, Polymer, 2014, 55, 6409-6417.

21 H. Xiu, X. Qi, Z. Liu, Y. Zhou, H. Bai, Q. Zhang and Q. Fu, Simultaneously reinforcing and toughening of polylactide/ carbon fibre composites via adding small amount of soft poly(ether)urethane, Compos. Sci. Technol., 2016, 127, 54-61.

22 B. Li, S. Gong and G. Wu, Polystyrene reinforced by selfwelded glass fibres: kinetics of polyamide 6 preferential segregation, Compos. Sci. Technol., 2011, 71, 1257-1265.

23 B. Li, Y. Zhang and G. Wu, Thermoplastics reinforced by selfwelded glass fibres: effect of interfacial affinity on preferential segregation, Polymer, 2013, 54, 2440-2449.

24 Z. Xiong, Y. Yang and J. Feng, Preparation and characterization of poly(lactic acid)/starch composites toughened with epoxidized soybean oil, Carbohydr. Polym., 2013, 92, 810-816.

25 L. Cartier, T. Okihara and Y. Ikada, Epitaxial crystallization and crystalline polymorphism of polylactides, Polymer, 2000, 41, 8909-8919.

26 O. Martin and L. Avérous, Poly(lactic acid): plasticization and properties of biodegradable multiphase systems, Polymer, 2001, 42, 6209-6219.

27 M. Avrami, Kinetics of Phase Change. I General Theory, J. Chem. Phys., 1939, 7, 1103-1112.

28 M. Avrami, Kinetics of Phase Change. II Transformationmilime Relations for Random Distribution of Nuclei, J. Chem. Phys., 1940, 8, 212-224.

29 M. Nofar, W. Zhu and C. B. Park, Crystallization Kinetics of Linear and Long-Chain-Branched Polylactide, Ind. Eng. Chem. Res., 2011, 50, 13789-13798.

$30 \mathrm{H}$. Xu, H. Fang and J. Bai, Preparation and Characterization of High-Melt-Strength Polylactide with Long-Chain Branched Structure through $\gamma$-Radiation-Induced Chemical Reactions, Ind. Eng. Chem. Res., 2014, 53, 1150-1159.

$31 \mathrm{H}$. Fang, F. Jiang and Q. Wu, Supertough polylactide materials prepared through in situ reactive blending with PEG-based diacrylate monomer, ACS Appl. Mater. Interfaces, 2014, 6, 13552-13563.

$32 \mathrm{H}$. H. Winter and F. Chambon, Analysis of Linear Viscoelasticity of a Crosslinking Polymer at the Gel Point, J. Rheol., 1986, 30, 367-382.

33 F. Chambon and H. H. Winter, Linear Viscoelasticity at the Gel Point of a Crosslinking PDMS with Imbalanced Stoichiometry, J. Rheol., 1987, 31, 683-697.

34 W. Li, Y. Zhang and J. Yang, Thermal annealing induced enhancements of electrical conductivities and mechanism for multiwalled carbon nanotubes filled poly(ethylene-cohexene) composites, ACS Appl. Mater. Interfaces, 2012, 4, 6468-6478.

35 Y. Song and Z. Qiang, Linear viscoelasticity of polymer melts filled with nano-sized fillers, Polymer, 2010, 51, 3262-3268.

36 P. G. Malchev, B. Norder and S. J. Picken, The strain dependence of the dynamic moduli of short fibre reinforced thermoplastic blends, J. Rheol., 2007, 51, 235-260.

37 L. Ma, L. Meng and G. Wu, Improving the interfacial properties of carbon fibre-reinforced epoxy composites by grafting of branched polyethyleneimine on carbon fibre surface in supercritical methanol, Compos. Sci. Technol., 2015, 114, 64-71.

38 D. Jiang, L. Liu and J. Long, Reinforced unsaturated polyester composites by chemically grafting amino-POSS onto carbon fibres with active double spiral structural spiralphosphodicholor, Compos. Sci. Technol., 2014, 100, 158-165. 